\title{
Role of Airway Epithelial Cells in Development of Chronic Obstructive Pulmonary Disease
}

\author{
Ling Ye, Xiangdong Wang and Meiling Jin*
}

Department of Respiration, ZhongShan Hospital, Fudan University, Shanghai, China

\begin{abstract}
Chronic obstructive pulmonary disease (COPD) is characterized by airflow limitation of peripheral airways that is not fully reversible. COPD is associated with airway remodeling, which thickens the airway walls and narrows the airway as a result. Exposure to cigarette smoke is the major risk factor for this condition. Pathogens including viruses and bacteria may induce COPD exacerbations. Now there is more evidence to suggest a significant relationship between airway epithelial cells and the pathogenesis of COPD. Airway epithelial cells make up an efficient barrier against pathogens and aggressive molecules. However, after exposure to cigarette smoke and pathogens, epithelial cells are stimulated to release a variety of pro-inflammatory mediators, including chemokines, cytokines, and growth factors through signaling pathways. These mediators recruit or stimulate other types of cells to induce an increased inflammatory response, production of mucus, and finally result in airway remodeling. After epithelium injury, epithelial cells participate in the process of repair and regeneration to maintain the epithelial integrity. A better understanding of the role of airway epithelial cells in COPD may be valuable to provide a basis for new therapeutic strategies.
\end{abstract}

Keywords: Airway epithelial cell, chronic obstructive pulmonary disease, inflammation, remodeling, wound repair.

\section{INTRODUCTION}

Chronic obstructive pulmonary disease (COPD) is a condition characterized by airflow limitation of peripheral airways that is not fully reversible and usually becomes progressively worse over time. The key determinants to this limit in airflow are an increase in the resistance of small conducting airways less than $2 \mathrm{~mm}$ in diameter and emphysematous destruction of the lung elastic recoil force available to drive expiratory flow [1]. COPD is typically associated with chronic bronchitis and emphysema. Inhalation of noxious particles or gases, particularly cigarette smoking (CS), is the major risk factor. Pathogens, including viruses and bacteria, may induce COPD exacerbation. COPD currently affects between approximately 10 and 24 million adults in the United States alone [2]. COPD is the fourth leading cause of death worldwide, and further increases in its prevalence and mortality rate are predicted [3].

\section{ANATOMY AND PHYSIOLOGICAL FUNCTION OF AIRWAY EPITHELIAL CELLS}

The surface of airway epithelium consists of ciliated cells, goblet cells, Clara cells and basal cells. Ciliated cells are found from the trachea to the last respiratory bronchiole, but their height decreases from pseudostratified columnar cells to simple columnar cells, and eventually cuboidal cells, with the reduction of the airway diameter. The frequency of goblet cells also decreases toward the periphery; until in the bronchioles, they are replaced by Clara cells. These airway epithelial cells make up an efficient barrier through intercellular epithelial junctions against pathogens and aggressive

*Address correspondence to this author at the Department of Respiration, ZhongShan Hospital, Fudan University, Shanghai, 180 Fenglin Road Shanghai China Post Code 200032, China; Tel: 13701640522;

Fax: 86-21-54961729; E-mail: mljin118@yahoo.com.cn molecules. Moreover, they exert important effects in airway defense mechanisms through mechanical clearance of the mucus, homeostasis of ion and water transport, biochemical antibacterial, antioxidant, antiprotease functions, and so on [4].

\section{ROLE OF AIRWAY EPITHELIAL CELLS IN CIGA- RETTE SMOKE EXPOSURE}

CS exposure is a key risk factor in the development of COPD and is identified as the primary cause of $80-90 \%$ of all COPD cases in the United States [5]. A series of studies have previously found that expression of Interleukin-8 (IL-8) and mucin was significantly increased and the barrier function (trans-epithelial electric resistance, TEER) was reduced when airway epithelial cells were exposed to CS [6-9]. The reduction of TEER reflects a breakdown of the epithelial integrity, which can affect the defense mechanisms of the airway. Further studies have confirmed that the epidermal growth factor receptor (EGFR) mediated the production of IL-8 and mucin induced by CS in airway epithelial cells $[8,9]$. Besides EGFR, niflumic acid-sensitive chloride channels (probably calcium-activated chloride channel) also affect the mucin production as a part of a single complex signaling pathway [10]. Then by activating the mitogenactivated protein kinase (MAPK) pathway in airway epithelial cells, nicotine contributes to the development and progression of the inflammatory reactions in COPD patients [11].

Baginski et al. have reported that CS induced early growth response gene 1 (Egr-1) to up-regulate in epithelial cells. Through the Egr-1-mediated mechanisms, proinflammatory cytokines, such as IL- $1 \beta$ and TNF- $\alpha$, were significantly up-regulated in pulmonary epithelial cells exposed to CS [12]. And then CS had the potential to amplify induction of respiratory mucins by pro-inflammatory stimuli. 
Reynolds et al. have reported that CS synergistically increased gene expression and protein production of MUC5AC mucin, which was not only induced by lipopolysaccharide (LPS), tumor necrosis factor- $\alpha$ (TNF- $\alpha$ ), and tumor growth factor- $\alpha$ (TGF- $\alpha)$, but also by amphiregulin in airway epithelial cells [13].

\section{ROLE OF AIRWAY EPITHELIAL CELLS IN THE INFECTIONS OF PATHOGENS}

Pathogens, including viruses and bacteria, can cause injury to the epithelial cells lining the airway, and then exacerbate COPD and accelerate deterioration of lung function. Acute exacerbations of COPD are major causes of hospitalizations and death, and account for $70 \%$ of health care costs for the disease [14].

Viruses such as rhinovirus (RV), influenza, parainfluenza, respiratory syncytial virus (RSV), adenovirus (AV), and coronavirus contribute to the exacerbation of COPD. Of these viruses, RV serves as the dominant viral pathogen [1518]. Respiratory viral infections are associated with COPD exacerbations that are more frequent, severe, and have longer recovery times [16].

The airway epithelial cell is the principle site of respiratory viral infection and plays a central role in viral modulation of airway inflammation through the release of cytokines, chemokines, and growth factors. Viruses enter into the epithelial cells based on interaction with host-cell surface receptors. RV attaches to epithelial cells through intercellular adhesion molecule-1 (ICAM-1), then enters into the cells. However, blockage of ICAM-1 may prevent RV infection
[19-21]. Following viral infection, many inflammatory mediators are produced from airway epithelial cells. For instance, RV infection has been shown to induce production of a variety of pro-inflammatory chemokines, including Epithelial neutrophil-activating protein-78 (ENA-78), IL-8, INF- $\gamma$ inducible protein 10 (IP-10), regulated on activation normal T-expressed and secreted proteins (RANTES), monocyte chemoattractant protein-1 (MCP-1), macrophage inflammatory protein-1 $\alpha$ (MIP-1 $\alpha$ ), as well as cytokines, such as IL-1, IL-6, IL-11, IL-16, TNF- $\alpha$, and granulocyte-macrophage colony-stimulating factor (GM-CSF) from epithelial cells $[15,20]$. These inflammatory mediators contribute to recruitment and activation of inflammatory cells including $\mathrm{T}$ cells, NK cells, macrophages and neutrophils, as shown in Fig. (1). Though such responses facilitate clearance of virus, these cells may also serve to amplify pre-existing inflammation, then induce a pulmonary and systemic inflammatory response, mucus hypersecretion and airway remodeling, all of which contribute to the exacerbation of COPD.

Further studies have confirmed that Toll-like receptor (TLRs)-3 and epidermal growth factor receptor (EGFR) were induced to increase double -stranded RNA responsiveness and inflammatory reaction in the airway epithelial cells after RV infection [22-25]. And then a series of signal transduction pathways, which take part in the control of transcriptional and post-transcriptional regulation of epithelial cytokine and chemokine production, are induced by viruses [24,26-30]. These signal transduction pathways includes Phosphatidylinositol 3-Kinase (PI3K), MAPK, STATs, Nuclear Factor- $\kappa \mathrm{b}(\mathrm{NF}-\kappa \mathrm{B})$ and so an. However, our under-

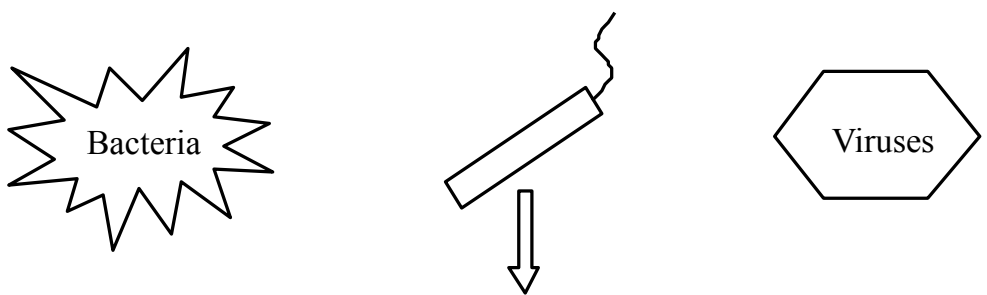

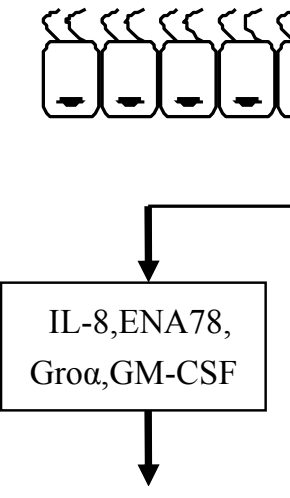

Neutrophils

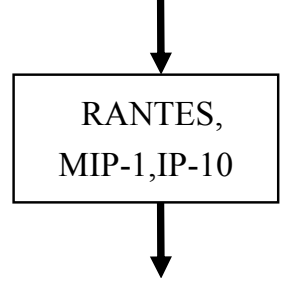

T Lymphocytes

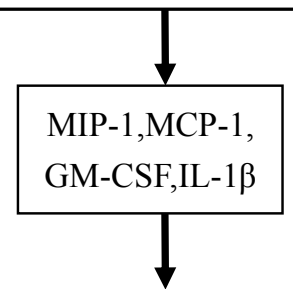

Mononuclear

Macrophages

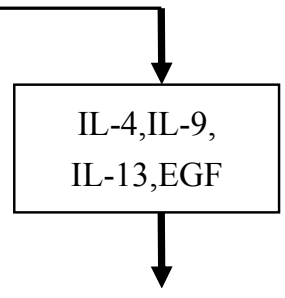

Fibroblasts

Fig. (1). Cigarette smoking and pathogens act on airway epithelium, then stimulate cells to release pro-inflammatory mediators. These mediators recruit or stimulate neutrophils, T lymphocytes, mononuclear macrophages, and fibroblasts, which induce a pulmonary and systemic inflammatory response, mucus hypersecretion, and airway remodeling. 
standing of the mechanisms by which viruses induce cytokine and chemokine production still remains limited.

Beside viruses, bacteria can also trigger exacerbations in patients with COPD by colonizing and infecting the lower respiratory tract $[31,32]$. Bacteria are capable of efficiently adhering and invading the airway epithelium, especially binding to damaged cells or cells still undergoing repair. Then such as $M$. catarrhalis and $H$. influenzae induce inflammatory response in airway epithelial cells through the MAPK and NF- $\kappa \mathrm{B}$ activation pathways, which is characterized by the release of IL-8, GM-CSF, IL-1 $\beta$, and TNF- $\alpha$ [3335]. Furthermore, Slevogt et al. have shown that the inflammatory response reduced by $M$. catarrhalis was of a strong time and dose dependent [35]. However, a prospective, longitudinal cohort study of patients with COPD has shown change in bacterial load was unlikely to be an important mechanism for exacerbations [36]. Therefor better understanding of the host-pathogen interaction, rather than enumerating bacteria in respiratory samples, is potentially required to provide new insights into bacterial infection in COPD.

As early as 1986, Plotkowski et al. have demonstrated that pneumococcal adherence to respiratory epithelium is maximal in the repairing migratory cells after viral infection [37]. Similarly, Sajjan U et al. have found that RV facilitated binding, translocation, and persistence of bacteria by disrupting airway epithelial barrier function [38]. Moreover, another study has shown $H$. influenzae infection increased the expression of the airway epithelial cell ICAM-1 and TLR3, leading to enhanced binding of RV and a potential for RVinduced chemokine release [39]. These data suggest bacteria and viruses may synergistically induce exacerbation of COPD.

\section{ROLE OF AIRWAY EPITHELIAL CELLS IN OXI- DATIVE STRESS}

Oxidative stress plays an important role in the pathogenesis of COPD, which contributes to oxidative inactivation of antiproteases and surfactants, mucus hypersecretion, membrane lipid peroxidation, alveolar epithelial injury, remodeling of extracellular matrix, and apoptosis [40]. As the physical barrier between submucosal tissues and the external environment, airway epithelial cells are the initial targets of reactive oxygen species (ROS), which are injured by oxidants inhaled as atmospheric pollutants or produced during inflammatory responses. Many previous studies have demonstrated that CS and pathogens could induce oxidative stress in airway epithelial cells, though airway epithelial cells could synthesize and secrete antioxidants such as glutathione peroxidase [32,41-44]. For example, Pierrou et al. have observed significant changes in oxidant response genes in vivo and vitro exposed to CS, some of which were further amplified in a nonlinear fashion, in COPD [41]. Another study has confirmed that RV infection induced depletion of reduced glutathione in epithelial cells by activating xanthine oxidase [44].

ROS to the airway epithelial cells increases the gene expression of cytokines, such as TNF-a, which in turn activate the cells to induce pro-inflammatory genes, such as TNF-a, IL-8, IL-1, iNOS, cyclooxygenase-2, ICAM-1, IL-6, MIP1a, GM-CSF, and stress response genes, such as heat shock protein (HSP)-27, 70, 90, hemeoxygenase-1 (HO-1), and antioxidant enzymes, such as glutamate cysteine ligase, MnSOD, and thioredoxin [45]. Rahman et al. have found that the levels of 4-hydroxy-2-nonenal-modified (4-HNE) proteins were increased in airway epithelial cells in subjects with COPD [46]. 4-HNE is a diffusible and highly reactive lipid peroxidation end-product, the modification of which results in abnormal regulation of cellular functions, such as cell proliferation and inhibition, T-cell apoptosis, and activation of various signaling pathways. Further studies have indicated that ROS was implicated in initiating inflammatory responses in the lungs through the activation of signal transduction pathways, such as the MAPK and PI-3K pathways, and transcription factors, such as NF- $\kappa \mathrm{B}$ and activator protein-1 (AP-1), leading to enhanced gene expression of proinflammatory mediators [45].

Because oxidative stress is implicated in the pathogenesis of COPD, therapeutic administration of antioxidants may be effective in the treatment of COPD. A study by Di Stefano et al. has demonstrated the expression of the p65 protein of $\mathrm{NF}-\kappa \mathrm{B}$ was increased in airway epithelium in COPD patients, which was correlated with the degree of airflow limitation [47]. A related study about the potential therapeutic effect of an small interfering RNA against p65 in airway epithelial cells has demonstrated the cells treated with TNF- $\alpha$ showed a reduced p65 expression and concomitant IL-6 and IL-8 expression $[40,45]$.

\section{ROLE OF AIRWAY EPITHELIAL CELLS IN MUCUS HYPERSECRETION}

With the progression of COPD, an association with mucus accumulation develops, though mucus acts as a physical barrier. In addition, polluted air, CS, pathogens can increase the production of mucus $[9,10,13,48-51]$. For instance, RV can increase the mucin production in epithelial cells by the MAPK or TLR3-EGFR-dependent pathway [48,50]. The surface epithelial goblet cells are the main source of secretory gelforming mucins in the airways, and the sub-mucosal glands serves as a secondary source. Since COPD mainly implicates in peripheral small airways, which do not contain sub-mucosal glands, it appears that goblet cells maybe play an important role in the initiation and development of COPD. Furthermore, the number of goblet cells also increase in COPD. Moreover, some cytokines influence the formation of goblet cells. For example, IL-1 $\beta$ increases MUC5AC expression and secretion in bronchial epithelial cells [51]. Some previous studies have demonstrated that the activation of EGFR increased goblet cells metaplasia and mucus production through MAPK and PI3K signaling pathway [5254].

Besides the oversecretion of mucus, the reduction of mucociliary clearance also results in mucus accumulation. $\mathrm{Mu}-$ cociliary clearance relies on appropriate interactions between the ciliated epithelium, the height of the periciliary fluid and mucus, which may be disrupted by viral and bacterial infections or by inhalation toxins and other causes [55]. It has been shown that ciliated cells represent approximately 25 $30 \%$ of surface epithelial cells in never-smokers, $10 \%$ in smokers with normal pulmonary function, and almost none in COPD patients [56]. 


\section{ROLE OF AIRWAY EPITHELIAL CELLS IN APOP- TOSIS}

Apoptosis, programmed cell death, is a physiologic mechanism for elimination of unnecessary, damaged, or infected cells. Many previous studies of patients with COPD have indicated a greater presence of apoptotic cells in the lungs than those in the control group [57-62]. These apoptotic cells include bronchial and alveolar epithelial cells, as well as endothelial cells in the parenchyma.

CS plays an important role in the process of apoptosis of airway epithelial cells. Even for the ex-smokers with COPD, there is no significant difference in apoptosis of airway epithelial cells between current and ex-smokers with COPD, which implies excess apoptosis persists after the cessation of smoking [63]. On the one hand, CS activates effector caspases ,stimulates proteases and chemokines, and induces epithelial apoptosis via IL-18R $\alpha$-dependent pathways [64]. Besides, CS decreases histone deacetylase activity, resulting in increased expression of autophagic proteins, which induces autophagy and apoptosis [65]. On the other hand, CS impairs the clearance of apoptotic cells by suppressing phagocytic ability of alveolar macrophages [66-68]. An inability to effectively remove apoptotic cells may not only be the result of post-apoptotic cytolysis (secondary necrosis), but also interfere with normal cell replacement [60]. CS inhibits efferocytosis through oxidant-dependent activation of the RhoA-Rho kinase pathway [67]. The process is a dose-dependent, reversible, and cell type-independent manner, whereas more intense CS exposure had an irreversible effect. HO-1 provides cytoprotection against oxidative stress. Recent studies have demonstrated that HO-1 protected against CS-induced cell death by downregulating apoptosis and autophagy-related signaling [68,69]. Moreover, CS causes the loss of cellular ATP and rapid depolarization of mitochondrial membrane potential, and then blockade of mitochondrial respiratory chain, which switches epithelial cells apoptosis into necrosis [70]. However, HO-1 has the potential role in defense against mitochondria mediated apoptosis during CS exposure [69].

\section{ROLE OF AIRWAY EPITHELIAL CELLS IN AIR- WAY REMODELING}

COPD is always associated with the remodeling of the airway epithelium, such as squamous metaplasia, mucous secretory cell hyperplasia, and mucus accumulation. This contributes to the decline of lung function, irreversible airflow obstruction, and predisposition of the patient to infection and hospitalization. The remodeling is the result of disruption in normal cell and tissue dynamics, which are caused by inhaled noxious particles or gases and pathogens, such as bacteria or viruses.

After injury, airway epithelial cells need to repair and regenerate to restore epithelial integrity and function in a rapid and dynamic manner. The current consensus is that many cells can contribute to repair of an injury, but that basal cells likely represent a stem cell compartment in the adult pseudostratified epithelium [71]. Besides basal cells, Clara cells may also be stem cells to restore the airway epithelium after injury. On the basis of studies in experimental animals and limited studies in humans, the process of repair and regeneration includes the spreading and migration of the basal cells neighboring the wound, proliferation and active mitosis, and squamous metaplasia, which is followed by progressive redifferentiation with the emergence of preciliated cells. The final step of the repair and regeneration process is ciliogenesis and complete regeneration of a pseudostratified mucociliary epithelium, as shown in Fig. (2) [71,72]. Lately, Park et al. have reported that in order to maintain the integrity of the epithelium of mice, ciliated epithelial cells transdifferentiated into squamous cells and spreaded beneath injured Clara cells within 6-12 hours of an injury, then transdifferentiated from squamous to cuboidal to columnar cell types as differentiation-specific cell markers typical of the mature airway were restored, as shown in Fig. (2) [73]. Though the study bases on animal model, it suggests human ciliated epithelial cells or other non-stem cells maybe have the same potential to repair the airway epithelium. Moreover, recently there are two studies identifying genes which mediate regeneration of human airway epithelial cells in vivo and in vitro respectively $[74,75]$. In vivo, Heguy et al. denuded the airway epithelium of healthy individuals, sequentially sampled the same region 7 and 14 days later. At 7 days compared with resting epithelium, there were substantial differences in gene expression pattern. The repair transcriptome was dominated by cell cycle, signal transduction, metabolism and transport, and transcription genes. However, at 14 days postinjury, the expression profile was similar to that of resting airway epithelium [74]. In vitro, Ross et al. cultured human bronchial epithelial cells over a 28-day period and identified over 2,000 genes that displayed statistically significant 2-fold or greater changes in expression during the time course. Many of these genes are involved in processes associated with airway epithelial biology, such as cell adhesion, immunity, transport, and cilia formation [75].

In the process of repair and regeneration, there are many cellular and molecular factors involved. In spreading and migration of the epithelial cells, the polymerization and accumulation of actin in the lamellipodia of the dedifferentiated and flattened basal cells results in forming adhesive contacts with the extracellular matrix (ECM). And then, by degrading components of the ECM, metalloproteases (MMPs) remodel the provisional matrix to allow migrating cells to form new contacts which may be used by cells to exert traction through actin filament bundles to move further along. MMPs such as MMP-7, MMP-9 play a key role in the migration to promote airway epithelial wound [76-81]. A further study has confirmed that it existed an exclusive expression of MMPs at the apical part of the well-differentiated regenerated airway epithelium, and incubation of the regenerating epithelial cells with MMP inhibitors leaded to an abnormal epithelial differentiation [81]. However, in this process, most of the bacteria identified in COPD bind especially to damaged cells or cells still undergoing repair. These bacteria also release virulence factors that impede or delay the migration of the epithelial cells and induce a disordered repair which undermines the epithelial barrier function. For instance, such as $H$. influenzae, $S$. pneumoniae, and $P$. aeruginosa can bind to ECM in areas of incomplete repair and virulence factors from $P$. aeruginosa and $S$. aureus induce actin skeleton disorganization and overactivation of MMP-2, which are responsible for delayed epithelial wound closure [4]. 


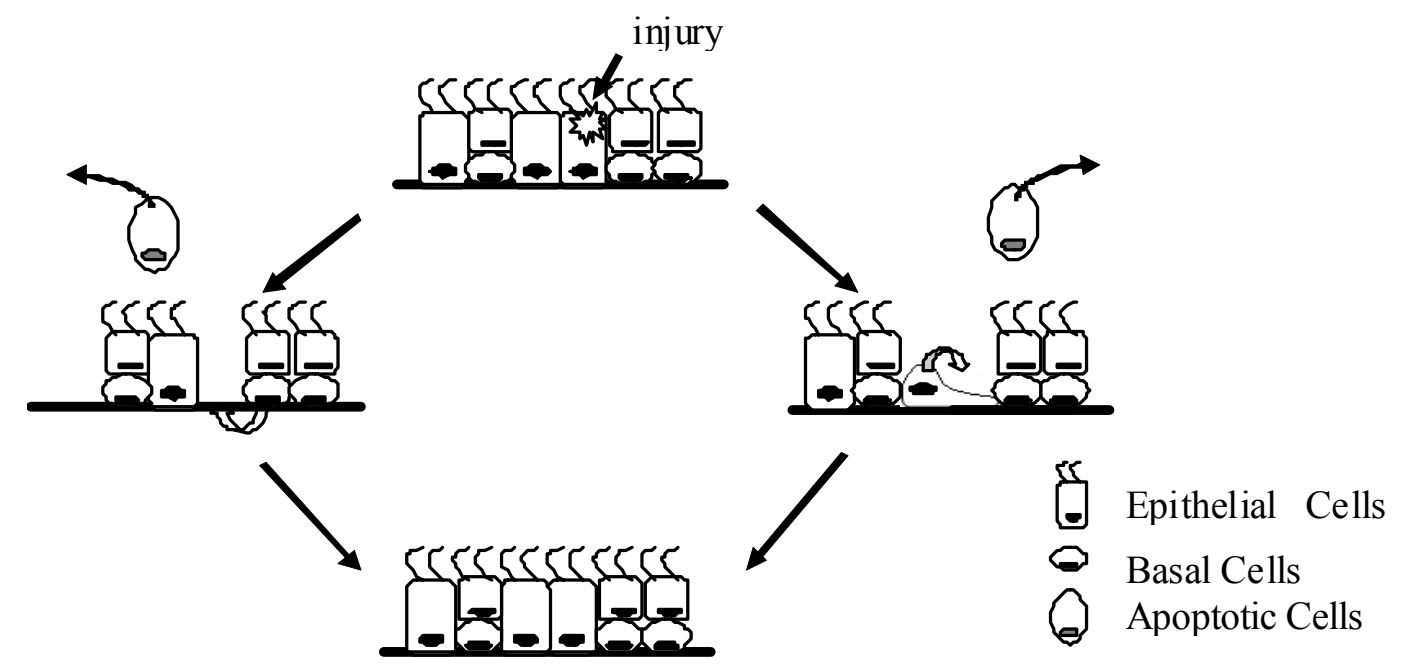

Fig. (2). Injury induces airway epithelial cells to undergo apoptosis and removal. Basal cells neighboring the wound participate in the process of repair and regeneration, including spread, migration, proliferation, squamous metaplasia, finally transdifferentiate mature epithelial cells. Ciliated epithelial cells also have the ability to spread and transdifferentiate into distinct epithelial cell types to repair the airway epithelium.

During injury and repair, epithelial cells also are able to secrete cytokines and growth factors. Coraux et al. have reported that during the cell migration and proliferation steps airway epithelial cells expressed IL-8 at a relatively high level, whereas airway epithelial pseudostratification and surface airway epithelium differentiation were associated with an increased expression of MMPs and a progressive decrease in the level of IL- 8 [81]. TGF- $\beta 1$ modulates the composition of the provisional matrix over which the epithelial cells migrate and has been shown to increase in airway wound repair through MMP-2 up-regulation [82].

\section{ACKNOWLEDGMENTS}

This research is supported by Shanghai Leading Academic Discipline Project, NO B115.

\section{REFERENCES}

[1] Hayashi S, Hogg JC. Adenovirus infections and lung disease. Curr Opin Pharmacol 2007; 7: 237-43.

[2] Mannino DM, Homa DM, Akinbami LJ, et al. Chronic obstructive pulmonary disease surveillance-United States, 1971-2000. MMWR Surveill Summ 2002; 51: 1-16.

[3] Murray CJ, Lopez AD. Evidence-based health policy-lessons from the Global Burden of Disease Study. Science 1996; 274: 740-3.

[4] Puchelle E, Zahm JM, Tournier JM, et al. Airway epithelial repair, regeneration, and remodeling after injury in chronic obstructive pulmonary disease. Proc Am Thorac Soc 2006; 3: 726-33.

[5] Sethi JM, Rochester CL. Smoking and chronic obstructive pulmonary disease. Clin Chest Med 2000; 21: 67-86.

[6] Glader P, Möller S, Lilja J, et al. Cigarette smoke extract modulates respiratory defence mechanisms through effects on T-cells and airway epithelial cells. Respir Med 2006; 100: 818-27.

[7] Rusznak C, Sapsford RJ, Devalia JL, et al. Cigarette smoke potentiates house dust mite allergen-induced increase in the permeability of human bronchial epithelial cells in vitro. Am J Respir Cell Mol Biol 1999; 20: 1238-50.

[8] Richter A, O'Donnell RA, Powell RM, et al. Autocrine ligands for the epidermal growth factor receptor mediate interleukin-8 release from bronchial epithelial cells in response to cigarette smoke. Am J Respir Cell Mol Biol 2002; 27: 85-90.

[9] Takeyama K, Jung B, Shim JJ, et al. Activation of epidermal growth factor receptors is responsible for mucin synthesis induced by cigarette smoke. Am J Physiol Lung Cell Mol Physiol 2001; 280: L165-72.
[10] Hegab AE, Sakamoto T, Nomura A, et al. Niflumic acid and AG1478 reduce cigarette smoke-induced mucin synthesis: the role of hCLCA1. Chest 2007; 131: 1149-56.

[11] Tsai JR, Chong IW, Chen CC, et al. Mitogen-activated protein kinase pathway was significantly activated in human bronchial epithelial cells by nicotine. DNA Cell Biol 2006; 25: 312-22.

[12] Reynolds PR, Cosio MG, Hoidal JR. Cigarette smoke-induced Egr1 upregulates proinflammatory cytokines in pulmonary epithelial cells. Am J Respir Cell Mol Biol 2006; 35: 314-9.

[13] Baginski TK, Dabbagh K, Satjawatcharaphong C, et al. Cigarette smoke synergistically enhances respiratory mucin induction by proinflammatory stimuli. Am J Respir Cell Mol Biol 2006; 35: 165-74.

[14] Pauwels RA, Buist AS, Calverley PM, et al. Global strategy for the diagnosis, management, and prevention of chronic obstructive pulmonary disease. NHLBI/WHO Global Initiative for Chronic Obstructive Lung Disease (GOLD) Workshop summary. Am J Respir Crit Care Med 2001; 163: 1256-76.

[15] Proud D, Chow CW. Role of viral infections in asthma and chronic obstructive pulmonary disease. Am J Respir Cell Mol Biol 2006; 35: 513-8.

[16] Seemungal T, Harper-Owen R, Bhowmik A, et al. Respiratory viruses, symptoms, and inflammatory markers in acute exacerbations and stable chronic obstructive pulmonary disease. Am J Respir Crit Care Med 2001; 164: 1618-23.

[17] Rohde G, Wiethege A, Borg I, et al. Respiratory viruses in exacerbations of chronic obstructive pulmonary disease requiring hospitalisation: a case-control study. Thorax 2003; 58: 37-42.

[18] Hutchinson AF, Ghimire AK, Thompson MA, et al.A communitybased, time-matched, case-control study of respiratory viruses and exacerbations of COPD. Respir Med 2007; 101: 2472-81.

[19] Hogg JC. Role of latent viral infections in chronic obstructive pulmonary disease and asthma. Am J Respir Crit Care Med 2001; 164(10 Pt 2):S71-75.

[20] Message SD, Johnston SL. Host defense function of the airway epithelium in health and disease: clinical background. J Leukoc Biol 2004; 75: 5-17.

[21] Wedzicha JA. Role of viruses in exacerbations of chronic obstructive pulmonary disease. Proc Am Thorac Soc 2004; 1: 115-20.

[22] Groskreutz DJ, Monick MM, Powers LS, et al. Respiratory syncytial virus induces TLR3 protein and protein kinase R, leading to increased double-stranded RNA responsiveness in airway epithelial cells. J Immunol 2006; 176: 1733-40.

[23] Chen Y, Hamati E, Lee PK, et al. Rhinovirus induces airway epithelial gene expression through double-stranded RNA and IFNdependent pathways. Am J Respir Cell Mol Biol 2006; 34: 192203. 
[24] Liu K, Gualano RC, Hibbs ML, et al. Epidermal growth factor receptor signaling to Erk1/2 and STATs control the intensity of the epithelial inflammatory responses to rhinovirus infection. J Biol Chem 2008; 283: 9977-85.

[25] Hewson CA, Jardine A, Edwards MR, et al. Toll-like receptor 3 is induced by and mediates antiviral activity against rhinovirus infection of human bronchial epithelial cells. J Virol 2005; 79: 12273-9.

[26] Newcomb DC, Sajjan U, Nanua S, et al. Phosphatidylinositol 3kinase is required for rhinovirus-induced airway epithelial cell interleukin-8 expression. J Biol Chem 2005; 280: 36952-61.

[27] Newcomb DC, Sajjan US, Nagarkar DR, et al. Human rhinovirus 1B exposure induces phosphatidylinositol 3-kinase-dependent airway inflammation in mice. Am J Respir Crit Care Med 2008; 177 : 1111-21.

[28] Griego SD, Weston CB, Adams JL, et al. Role of p38 mitogenactivated protein kinase in rhinovirus-induced cytokine production by bronchial epithelial cells. J Immunol 2000; 165: 5211-20.

[29] Pazdrak K, Olszewska-Pazdrak B, Liu T, et al. MAPK activation is involved in posttranscriptional regulation of RSV-induced RANTES gene expression. Am J Physiol Lung Cell Mol Physiol 2002; 283: L364-72.

[30] Zhu Z, Tang W, Gwaltney JM Jr, et al. Rhinovirus stimulation of interleukin-8 in vivo and in vitro: role of NF-kappaB. Am J Physiol 1997; 273(4 Pt 1): L814-24.

[31] Murphy TF, Sethi S, Niederman MS. The role of bacteria in exacerbations of COPD. A constructive view. Chest 2000; 118: 204-9.

[32] Murphy TF. The role of bacteria in airway inflammation in exacerbations of chronic obstructive pulmonary disease. Curr Opin Infect Dis 2006; 19: 225-30.

[33] Shuto T, Xu H, Wang B, et al. Activation of NF-kappa B by nontypeable Hemophilus influenzae is mediated by toll-like receptor 2TAK1-dependent NIK-IKK alpha /beta-I kappa B alpha and MKK3/6-p38 MAP kinase signaling pathways in epithelial cells. Proc Natl Acad Sci USA 2001; 98: 8774-9.

[34] Watanabe T, Jono H, Han J, et al. Synergistic activation of NFkappaB by nontypeable Haemophilus influenzae and tumor necrosis factor alpha. Proc Natl Acad Sci USA 2004; 101: 3563-8.

[35] Slevogt H, Schmeck B, Jonatat C, et al. Moraxella catarrhalis induces inflammatory response of bronchial epithelial cells via MAPK and NF-kappaB activation and histone deacetylase activity reduction. Am J Physiol Lung Cell Mol Physiol 2006; 290: L81826.

[36] Sethi S, Sethi R, Eschberger K, et al. Airway bacterial concentrations and exacerbations of chronic obstructive pulmonary disease. Am J Respir Crit Care Med 2007; 176: 356-61.

[37] Plotkowski MC, Puchelle E, Beck G, et al. Adherence of type I Streptococcus pneumoniae to tracheal epithelium of mice infected with influenza A/PR8virus. Am Rev Respir Di 1986; 134: 1040-4.

[38] Sajjan U, Wang Q, Zhao Y, et al. Rhinovirus disrupts the barrier function of polarized airway epithelial cells. Am J Respir Crit Care Med 2008; 178: 1271-81.

[39] Sajjan US, Jia Y, Newcomb DC, et al. Influenzae potentiates airway epithelial cell responses to rhinovirus by increasing ICAM-1 and TLR3 expression. FASEB J 2006; 20: 2121-3.

[40] Rahman I, Kilty I. Antioxidant therapeutic targets in COPD. Curr Drug Targets 2006; 7: 707-20.

[41] Pierrou S, Broberg P, O'Donnell RA, et al. Expression of genes involved in oxidative stress responses in airway epithelial cells of smokers with chronic obstructive pulmonary disease. Am J Respir Crit Care Med 2007; 175: 577-86.

[42] Fields WR, Leonard RM, Odom PS, et al. Gene expression in normal human bronchial epithelial (NHBE) cells following in vitro exposure to cigarette smoke condensate. Toxicol Sci 2005; 86: 8491.

[43] Biagioli MC, Kaul P, Singh I, et al. The role of oxidative stress in rhinovirus induced elaboration of IL- 8 by respiratory epithelial cells. Free Radic Biol Med 1999; 26: 454-62.

[44] Papi A, Contoli M, Gasparini P, et al. Role of xanthine oxidase activation and reduced glutathione depletion in rhinovirus induction of inflammation in respiratory epithelial cells. J Biol Chem 2008; 283: 28595-606.

[45] Rahman I, Adcock IM. Oxidative stress and redox regulation of lung inflammation in COPD. Eur Respir J 2006; 28: 219-42.

[46] Rahman I, Van Schadewijk AA, Crowther A, et al. 4-Hydroxy-2nonenal, a specific lipid peroxidation product is elevated in lungs of patients with chronic obstructive pulmonary disease (COPD). Am J Respir Crit Care Med 2002; 166: 490-5.

[47] Di Stefano A, Caramori G, Oates T, et al. Increased expression of NF-kappaB transcription factor in bronchial biopsies of smokers and patients with chronic obstructive pulmonary disease. Eur Respir J 2002; 20: 556-63.

[48] Inoue D, Yamaya M, Kubo H, et al. Mechanisms of mucin production by rhinovirus infection in cultured human airway epithelial cells. Respir Physiol Neurobiol 2006; 154: 484-99.

[49] Miller AL, Strieter RM, Gruber AD CXCR2 regulates respiratory syncytial virus-induced airway hyperreactivity and mucus overproduction. J Immunol 2003; 170: 3348-56.

[50] Zhu L, Lee PK, Lee WM, et al. Rhinovirus-induced major airway mucin production involves a novel TLR3-EGFR-dependent pathway. Am J Respir Cell Mol Biol 2009; 40: 610-9.

[51] Danahay H, Jackson AD. Epithelial mucus-hypersecretion and respiratory disease. Curr Drug Targets Inflamm Allergy 2005; 4: 651-64.

[52] Tyner JW, Kim EY, Ide K, et al. Blocking airway mucous cell metaplasia by inhibiting EGFR antiapoptosis and IL-13 transdifferentiation signals. J Clin Invest 2006; 116: 309-21.

[53] Casalino-Matsuda SM, Monzón ME, Forteza RM. Epidermal growth factor receptor activation by epidermal growth factor mediates oxidant-induced goblet cell metaplasia in human airway epithelium. Am J Respir Cell Mol Biol 2006; 34: 581-91.

[54] Zhen G, Park SW, Nguyenvu LT, et al. IL-13 and epidermal growth factor receptor have critical but distinct roles in epithelial cell mucin production. Am J Respir Cell Mol Biol 2007; 36: 24453.

[55] Stannard W, O'Callaghan C. Ciliary function and the role of cilia in clearance. J Aerosol Med 2006; 19: 110-5.

[56] Rusznak C, Mills PR, Devalia JL, et al. Effect of cigarette smoke on the permeability and IL-1beta and sICAM-1 release from cultured human bronchial epithelial cells of never-smokers, smokers, and patients with chronic obstructive pulmonary disease. Am J Respir Cell Mol Biol 2000; 23: 530-6.

[57] Hodge S, Hodge G, Scicchitano R, et al. Alveolar macrophages from subjects with chronic obstructive pulmonary disease are deficient in their ability to phagocytose apoptotic airway epithelial cells. Immunol Cell Biol 2003; 81: 289-96.

[58] Yokohori N, Aoshiba K, Nagai A. Increased levels of cell death and proliferation in alveolar wall cells in patients with pulmonary emphysema. Chest 2004; 125: 626-32.

[59] Imai K, Mercer BA, Schulman LL, et al. Correlation of lung surface area to apoptosis and proliferation in human emphysema. Eur Respir J 2005; 25: 250-8.

[60] Henson PM, Vandivier RW, Douglas IS. Cell death, remodeling, and repair in chronic obstructive pulmonary disease? Proc Am Thorac Soc 2006; 3: 713-7.

[61] Park JW, Ryter SW, Choi AM. Functional significance of apoptosis in chronic obstructive pulmonary disease. COPD 2007; 4: 347-53.

[62] Sharafkhaneh A, Hanania NA, Kim V. Pathogenesis of emphysema: from the bench to the bedside. Proc Am Thorac Soc 2008; 5: 475-7.

[63] Hodge S, Hodge G, Holmes M, et al. Increased airway epithelial and T-cell apoptosis in COPD remains despite smoking cessation. Eur Respir J 2005; 25: 447-54.

[64] Kang MJ, Homer RJ, Gallo A, et al. IL-18 is induced and IL-18 receptor alpha plays a critical role in the pathogenesis of cigarette smoke-induced pulmonary emphysema and inflammation. J Immunol 2007; 178: 1948-59.

[65] Chen ZH, Kim HP, Sciurba FC, et al. Egr-1 regulates autophagy in cigarette smoke-induced chronic obstructive pulmonary disease. PLoS One 2008; 3: e3316.

[66] Hodge S, Hodge G, Ahern J, et al. Smoking alters alveolar macrophage recognition and phagocytic ability: implications in chronic obstructive pulmonary disease. Am J Respir Cell Mol Biol 2007; 37:748-55.

[67] Richens TR, Linderman DJ, Horstmann SA, et al. Cigarette smoke impairs clearance of apoptotic cells through oxidant-dependent activation of RhoA. Am J Respir Crit Care Med 2009; 179: 1011-21.

[68] Kim HP, Wang X, Chen ZH, et al. Autophagic proteins regulate cigarette smoke-induced apoptosis: protective role of heme oxygenase-1. Autophagy 2008; 4: 887-95. 
[69] Slebos DJ, Ryter SW, van der Toorn M, et al. Mitochondrial localization and function of heme oxygenase-1 in cigarette smokeinduced cell death. Am J Respir Cell Mol Biol 2007; 36:409-17.

[70] van der Toorn M, Slebos DJ, de Bruin HG, et al. Cigarette smokeinduced blockade of the mitochondrial respiratory chain switches lung epithelial cell apoptosis into necrosis. Am J Physiol Lung Cell Mol Physiol 2007; 292: L1211-8.

[71] Randell SH. Airway epithelial stem cells and the pathophysiology of chronic obstructive pulmonary disease. Proc Am Thorac Soc 2006; 3: 718-25.

[72] Puchelle E, Zahm JM, Tournier JM, et al. Airway epithelial repair, regeneration, and remodeling after injury in chronic obstructive pulmonary disease. Proc Am Thorac Soc 2006; 3: 726-33.

[73] Park KS, Wells JM, Zorn AM, et al. Transdifferentiation of ciliated cells during repair of the respiratory epithelium. Am J Respir Cell Mol Biol 2006; 34: 151-7.

[74] Heguy A, Harvey BG, Leopold PL, et al. Responses of the human airway epithelium transcriptome to in vivo injury. Physiol Genomics 2007; 29:139-48.

[75] Ross AJ, Dailey LA, Brighton LE, et al. Transcriptional profiling of mucociliary differentiation in human airway epithelial cells. Am J Respir Cell Mol Biol 2007; 37:169-85.
[76] Coraux C, Roux J, Jolly T, et al. Epithelial cell-extracellular matrix interactions and stem cells in airway epithelial regeneration. Proc Am Thorac Soc 2008; 5:689-94.

[77] Legrand C, Gilles C, Zahm JM, et al. Airway epithelial cell migration dynamics. MMP-9 role in cell-extracellular matrix remodeling. J Cell Biol 1999; 146: 517-29.

[78] Bove PF, Wesley UV, Greul AK, et al. Nitric oxide promotes airway epithelial wound repair through enhanced activation of MMP9. Am J Respir Cell Mol Biol 2007; 36: 138-46.

[79] McGuire JK, Li Q, Parks WC. Matrilysin (matrix metalloproteinase-7) mediates E-cadherin ectodomain shedding in injured lung epithelium. Am J Pathol 2003; 162: 1831-43.

[80] Chen P, McGuire JK, Hackman RC, et al. Tissue inhibitor of metalloproteinase-1 moderates airway re-epithelialization by regulating matrilysin activity. Am J Pathol 2008; 172: 1256-70.

[81] Coraux C, Martinella-Catusse C, Nawrocki-Raby B, et al. Differential expression of matrix metalloproteinases and interleukin-8 during regeneration of human airway epithelium in vivo. J Pathol 2005; 206: 160-9.

[82] Lechapt-Zalcman E, Pruliere-Escabasse V, Advenier D, et al. Transforming growth factor-betal increases airway wound repair via MMP-2 upregulation: a new pathway for epithelial wound repair? Am J Physiol Lung Cell Mol Physiol 2006; 290: L1277-82.

Received: June 07, 2009

(C) Ye et al.; Licensee Bentham Open.

This is an open access article licensed under the terms of the Creative Commons Attribution Non-Commercial License (http://creativecommons.org/licenses/by-nc/3.0/) which permits unrestricted, non-commercial use, distribution and reproduction in any medium, provided the work is properly cited. 